\title{
Assessment of adherence to highly active antiretroviral therapy and associated factors among people living with HIV at Debrebrihan Referral Hospital and Health Center, Northeast Ethiopia: a cross-sectional study
}

This article was published in the following Dove Press journal:

HIVIAIDS - Research and Palliative Care

II March 2015

Number of times this article has been viewed

\author{
Abush Kebede Ketema' \\ Zewdu Shewangizaw Weret ${ }^{2}$ \\ 'Regional Monitoring and Evaluation \\ Advisor, Management Sciences for \\ Health, Addis Ababa, Ethiopia; \\ ${ }^{2}$ College of Medicine and Health \\ Sciences, Arbaminch University, \\ Arbaminch, Ethiopia
}

\begin{abstract}
Patient adherence to antiretroviral combination therapy is a critical component to successful treatment outcome. Nonadherence to antiretroviral therapy (ART) is a major challenge to AIDS care, and the risks associated with it are extensive. The intention of this study was to determine prevalence and associated factors with adherence to highly active ART among people living with HIV/AIDS (PLWHA) at the Debrebrihan Referral Hospital and Health Center, Northeast Ethiopia. A cross-sectional study design with systematic random sampling conducted by the use of a structured, pretested self-rating adherence questionnaire was used to conduct the study among 422 respondents from the Debrebrihan Referral Hospital and Health Center. A single population proportion formula at $95 \%$ CI with $5 \%$ of marginal error at $50 \%$ of prevalence of occurrence was used to determine sample size. Adherence was defined as not missing a single ART dose during the 30-day period prior to filling out the self-report. Adherence was measured by self-reports by the patients. These results were then used in binary logistic regression analysis. Covariates were analyzed by bivariate and multivariate logistic regression with SPSS statistical software. The total number of respondents in this study was 422; their median age was 35 years. Among the participants, 95.5\% were taking their medication without missing a dose. Factors such as having emotional or practical support positively encouraged ART adherence (adjusted odds ratio 0.16 [95\% CI 0.05-0.49]). However, users of traditional, complementary, and alternative medicine (TCAM) (adjusted odds ratio 4.7 [95\% CI 1.06-21.22]) had nearly a five times higher risk for ART nonadherence $(P<0.05)$ than those not using TCAM. Adherence to ART among PLWA is imperative and standard. But, there is still a need to boost psychological support and practical support for the clients, and there is also a need to create a more integrative approach with TCAM in order to increase adherence to ART. Strengthening emotional and practical support for PLWHA and integrating TCAM with the proper use of ART are mandatory to enhance ART adherence.
\end{abstract}

Keywords: people living with HIV, adherence, holy water, traditional medicine, complementary medicine, alternative medicine

\section{Introduction}

AIDS is one of the top three causes of mortality worldwide and the primary cause of death in sub-Saharan Africa. Estimates of new infections in 2007 indicate that twothirds of them occurred in sub-Saharan Africa. More than $68 \%$ of adults and nearly 
$90 \%$ of children infected with HIV live in this region, and the fact that more than $76 \%$ of AIDS-related deaths in 2007 occurred there illustrates the unmet need for antiretroviral therapy (ART) in Africa. ${ }^{1}$

The HIV/AIDS epidemic is a serious threat to Ethiopian social and economic development. ${ }^{2}$ Ethiopia's HIV/AIDS epidemic pattern continues to be generalized and heterogeneous with marked regional variations. Despite the overwhelming challenges, the government of Ethiopia is making efforts towards containing the epidemic and mitigating the impact of HIV/AIDS through an intensified national response in a comprehensive and accelerated manner. Chronic HIV care that includes ART services is being provided in public, private, armed forces, police, and prison health facilities. Because the only sure way to stop the HIV epidemic is by preventing new infections, the government of Ethiopia attaches serious weight to HIV prevention followed by care, support, and treatment. ${ }^{2}$

Patient adherence to antiretroviral (ART) combination therapy is a critical component to successful treatment outcome because HIV is highly mutable and requires lifelong treatment. Nonadherence is a global problem and has been seen in all diseases. ${ }^{3}$ Patient adherence to ARV combination therapy is a critical component to successful treatment outcome. While combination therapy is known to be effective in slowing disease progression, the long term benefit of these therapies can only be sustained if resistant strains of HIV do not emerge among conditions that can result in the emergence of resistance. Customary practices, such as fasting, holy water use, and spiritual beliefs of the patient, may influence the adherence level. ${ }^{4}$

Moreover, factors associated with holy water use and ARV drug adherence were individual beliefs about ART, complementary and alternative medicine, spiritual beliefs (eg, calling on God for help), lack of communication and information about ART, lack of follow up and counseling, forgetfulness, stigma and discrimination due to disclosure of HIV status, lack of nutritional support, travel, adverse effects of drugs, and beliefs about mind and body. ${ }^{5-10}$

Ethiopia is one of the developing countries in which traditional medicine is used for primary health care by about $90 \%$ of the population. ${ }^{11}$ Traditional, complementary, and alternative medicine (TCAM) is commonly practiced by people living with HIV/AIDS (PLWHA), and 95\% of health care providers were not aware that their patients were taking traditional treatment. ${ }^{12}$

A growing number of PLWHA in Ethiopia today are relocating to holy water sites in search of spiritual care. The use of holy water is considered by them to be an alternative and complementary treatment for HIV/AIDS. ${ }^{13}$ There are people who believe that the only solution to HIV/AIDS is holy water and they do not want to use ART, and a majority of holy water users believe that HIV/AIDS is caused by an evil spirit or a demon by itself. The lack of awareness of the seriousness of this health problem and the encouragement by religious leaders to use holy water are considered to be reasons to stop taking medication. ${ }^{14}$

Although there have been studies done in Ethiopia on HIV/AIDS treatment adherence and its correlates, there were no still adequate studies found to indicate the impact of using holy water as complementary medicine on patient adherence. Therefore, this study aimed to determine prevalence and factors with adherence to highly active antiretroviral therapy (HAART) among PLWHA at the Debrebrihan Referral Hospital and Health Center, Northeast Ethiopia.

\section{Methods}

An institution-based, cross-sectional study of participants who were taking HAART at the Debrebrihan Referral Hospital and Health Center, Northeast Ethiopia was conducted by using a quantitative data collection technique. The sample size was calculated by using a single population proportion formula to estimate with a 0.05 margin of error and a $50 \%$ proportion of event occurrence with a $10 \%$ nonresponse rate. Based on the above assumption, the minimum sample size required for the study was 422 . The study subjects were selected by using systematic random sampling techniques on patient registration charts at the ART service provision health facilities for the specific day. The questionnaire was designed from previous studies done for assessing adherence; it included important variables for the study and was organized by sections for sociodemographics, social support, perception of ART, adherence, and use of complementary treatment. The tool was also checked for clarity and consistency; it was pretested in two health facilities (a nearby health center and a hospital) on a total of 22 patients to address any unclear or misunderstood questions and to allow corrections to be made on the tool. Adherence was defined as a patient self-reporting not having missed at least one ARV dose in during the 30 days preceding the completion of the report; having missed at least one ARV dose or two consecutive doses in the 30 days preceding the interview was scored as nonadherent. Holy water was defined as use of water blessed by a priest and used for treatment of HIV/AIDS by clients.

All of the adult HIV/AIDS patients in the study were attending one of the two health facilities and were at least 
18 years of age, able to hear, mentally fit, not seriously sick, and had started to take the ART included in the study. The study participants were approached by trained health professionals who were working in the ART clinic in each of the respective health facilities. The participants recruited into this study were on ART follow-up at the Debrebrihan Referral Hospital and Health Center at the time of our visit; were present during the study after patient confidentiality, benefits and risks to participating patients, justice, rights, and respect were addressed; were willing to participate in the study; and signed an informed consent.

Data analysis was done by using SPSS statistical software for descriptive variables. Binary logistic regression was undertaken to explore the factors associated with adherence at a significance of $P<0.05$ to provide odds ratios with a $95 \%$ confidence interval (CI). Bivariate associations between dependent and independent variables were conducted, and covariates with $P>0.2$ with the outcome variable were dropped from further consideration in modeling. Ethical clearance was obtained from the Amhara Regional State Health Bureau and the Zonal Health Bureau. Moreover, the results were disseminated to the responsible bodies who were involved in the health care activities of PLWHA.

\section{Results}

\section{Sociocultural and demographic characteristics of study participants}

There were 422 patients involved in the study, which had a $100 \%$ response rate. The median age of the respondents was 35 years; most of the respondents were females (262 [62.1\%]), and $160(37.9 \%)$ were married. Regarding educational status, 201 (47.7\%) has completed primary education. The majority were Orthodox Christian (390 [92\%]); $354(83.9 \%)$ were living in town, and $368(87.2 \%)$ were unemployed.

\section{TCAM use of PLWHA}

According to the results of the current study, 291 (69\%) respondents used treatments in addition to HAART to treat $\mathrm{HIV}$ and associated problems. Among the 291 respondents, $282(97 \%)$ used traditional medicine and 9 (3\%) used conventional medicine. The main reason for using additional medicines was to treat opportunistic infection (101 [34.7\%]), for spiritual relief (100 [34.4\%]), and to treat side effects (47 [16.2\%]). Also, 22 (7.6\%) study participants used TCAM with ART but did not disclose the use to their physicians. The majority of respondents (411 [97.4\%]) said that they attend a spiritual place; among these patients, 213 (51.8\%) attend occasionally and 147 (35.8\%) on a weekly basis. Prayer and use of holy water were the main reasons for being in spiritual places (113 [27.5\%]). Fifty-two (12.7\%) of the respondents faced the problem of taking medication according to the schedule while they were attending spiritual places; 25 of these patients $(48.1 \%)$ responded that they did not take their medication because of the fear of taking ARV drugs at a religious place.

Among all of the respondents, 252 (59.7\%) said that they have practiced fasting; among these, 122 (48.4\%) said that the medication schedule did not fit with the fasting period, $60(49.2 \%)$ took the medication without food, $54(44.2 \%)$ shifted the time, and $8(6.6 \%)$ missed the dose. A significant number of respondents (282 [66.8\%]) had the experience of using holy water while they were taking ARV drugs. Among respondents using additional treatments, 73 (25.9\%) said that it is not convenient to take medication while using holy water; out of those 73 respondents, 51 (69.9\%) said the main reason for this was the fear of using ARV drugs and holy water together. Regarding spiritual believes among the 422 respondents, 206 (48.8\%) believe that prayer can cure HIV, and $160(37.9 \%)$ agreed that HIV is a result of sin or punishment from God. In addition, 136 (32.2\%) of the respondents disclosed their status to religious leaders (Table 1).

\section{Level of adherence and reason for nonadherence}

In this study, each ARV user was asked to report his or her adherence rate within the past 3, 7, and 30 days. Among the study participants, 403 had adherence rates of $95.5 \%$, and the remaining 19 subjects $(4.5 \%)$ had missed at least one dose during the 30-day period prior to filling out the report.

\section{Factors associated with adherence}

Bivariate analysis was done to look for associations between all potential variables from this study and self-reported adherence for the 30-day period prior to completing the report. It was found that not all of the selected sociodemographic factors were associated with adherence. Regarding sociocultural factors, disclosure, the perception of something good happening after disclosure, the use of TCAM treatment, and spiritual/religious practices and beliefs were not found to be associated with adherence. However, something bad happening after disclosure was statistically associated with adherence (corrected odds ratio [COR] 4.8 [95\% CI 1.61-14.59]). Emotional or practical support (COR 0.19 [95\% CI 0.07-0.55]) and being fully convinced of the need for ART (accepting diagnosis) (COR 0.09 [95\% CI 
Table I Sociocultural characteristics of 422 respondents with HIVIAIDS

\begin{tabular}{|c|c|c|}
\hline Variables & Frequency (n) & Percentage (\% \\
\hline \multicolumn{3}{|c|}{ Disclosed HIV status to others } \\
\hline Yes & 357 & 84.6 \\
\hline No & 65 & 15.4 \\
\hline \multicolumn{3}{|c|}{ Emotional/practical support } \\
\hline Yes & 267 & 63.3 \\
\hline No & 155 & 36.7 \\
\hline \multicolumn{3}{|c|}{ Uses complementary treatment } \\
\hline Yes & 291 & 69 \\
\hline No & $13 \mid$ & 31 \\
\hline \multicolumn{3}{|c|}{ Type of complementary treatment } \\
\hline Traditional & 282 & 96.9 \\
\hline Conventional** & 9 & 3.1 \\
\hline \multicolumn{3}{|c|}{ Attends religious place } \\
\hline Yes & 411 & 97.4 \\
\hline No & 11 & 2.6 \\
\hline \multicolumn{3}{|l|}{ Fasts } \\
\hline Yes & 252 & 59.7 \\
\hline No & 170 & 40.3 \\
\hline \multicolumn{3}{|c|}{ Believes in cure by prayer } \\
\hline Yes & 206 & 48.8 \\
\hline No & 216 & 51.2 \\
\hline \multicolumn{3}{|c|}{ Believes HIV is punishment from God for sin } \\
\hline Yes & 160 & 37.9 \\
\hline No & 262 & 62.1 \\
\hline
\end{tabular}

Notes: All respondents were from the Debrebrihan Referral Hospital and Health Center, Northeast Ethiopia. **Use of conventional medicine was separated from traditional complementary treatment because conventional medicine was mostly provided by the health facility. Data were collected between December $201 \mathrm{I}$ and January 2012.

Abbreviation: $\mathrm{n}$, number of respondents.

0.08-1.04]) were also statistically associated with adherence (Table 2). Variables that had $P<0.2$ in the binary logistic regression analysis were also re-evaluated by using multivariate analysis with adherence as a dependent variable. A different set of variables was found to be associated with adherence by using the multivariate analysis. Disclosure and being fully convinced of the need for ARV were not statistically or significantly associated with adherence.

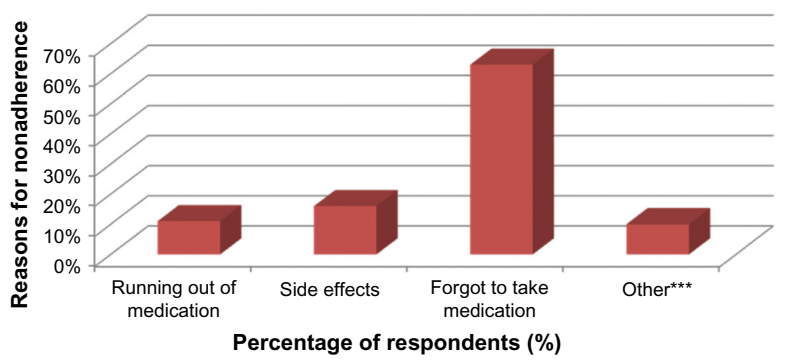

Figure I Reasons for nonadherence to ART among 422 respondents from the Debrebrihan Referral Hospital and Health Center, Northeast Ethiopia.

Notes: ***Being away from home, use of TCAM, or feeling better. Data collected between December 2011 and January 2012.

Abbreviations: ART, antiretroviral therapy; TCAM, traditional, complementary, and alternative medicine.
Table 2 Associations between sociocultural factors and adherence to HAART among 422 respondents with HIVIAIDS

\begin{tabular}{|c|c|c|c|}
\hline \multirow[t]{2}{*}{ Variables } & \multicolumn{2}{|c|}{$\begin{array}{l}\text { Adhered to } \\
\text { HAART (n) }\end{array}$} & \multirow[t]{2}{*}{$\begin{array}{l}\text { COR } \\
(95 \% \mathrm{Cl})\end{array}$} \\
\hline & Yes & No & \\
\hline \multicolumn{4}{|c|}{ Disclosed HIV status } \\
\hline Yes & 357 & 14 & I \\
\hline No & 65 & 5 & $2(0.7 I, 5.88)$ \\
\hline \multicolumn{4}{|c|}{ Something good happening after disclosure } \\
\hline Yes & 302 & 13 & 1 \\
\hline No & 41 & I & $0.57(0.72,4.45)$ \\
\hline \multicolumn{4}{|c|}{ Something bad happening after disclosure } \\
\hline Yes & 46 & 6 & $4.8(1.61,14.59)$ \\
\hline No & 267 & 8 & I \\
\hline \multicolumn{4}{|c|}{ Emotional/practical support } \\
\hline Yes & $14 \mid$ & 14 & 1 \\
\hline No & 262 & 5 & $0.19(0.07,0.55)$ \\
\hline \multicolumn{4}{|c|}{ Fully convinced of the need for ART } \\
\hline Yes & 401 & 18 & I \\
\hline No & 2 & 1 & $0.09(0.08,1.04)$ \\
\hline \multicolumn{4}{|c|}{ Uses traditional/complementary treatment } \\
\hline Yes & 274 & 17 & $0.25(0.57, I .1)$ \\
\hline No & 129 & 2 & 1 \\
\hline \multicolumn{4}{|l|}{ Fasts } \\
\hline Yes & 239 & 13 & $1.49(0.55,3.99)$ \\
\hline No & 164 & 6 & I \\
\hline \multicolumn{4}{|c|}{ Believes HIV is cured with prayer } \\
\hline Yes & 195 & 11 & 1 \\
\hline No & 208 & 8 & $0.68(0.27, \mathrm{I} .73)$ \\
\hline \multicolumn{4}{|c|}{ Believes HIV is punishment or a result of sin } \\
\hline Yes & 153 & 7 & $0.95(0.37,2.47)$ \\
\hline No & 250 & 12 & I \\
\hline
\end{tabular}

Notes: Study participants were from Debrebrihan Referral Hospital and Health Center, Northeast Ethiopia. Data were collected between December $201 \mathrm{I}$ and January 2012.

Abbreviations: HAART, highly active antiretroviral therapy; $n$, number of respondents; COR, corrected odds ratio; $\mathrm{Cl}$, confidence interval; ART, antiretroviral therapy.

The others factors, having emotional and practical support (AOR 0.16 [95\% CI 0.05-0.49]) and TCAM (AOR 4.7 [95\% CI 1.06-21.22]), were significantly associated. This shows that the rate of nonadherence among TCAM users is almost five times higher than the rate among non-TCAM users (Table 3 ).

\section{Discussion}

\section{Adherence to ART among PLWHA}

The present study aimed to investigate the prevalence and factors associated with HAART adherence. The current study has shown a high level of adherence in a large proportion of $\mathrm{HIV} /$ AIDS patients (95.5\%, 95\% CI [93.19\%-97.19\%]). The study finding is consistent with other studies conducted in resourcelimited settings, and the overall rate of adherence in this study is greater than those reported from previous studies..$^{8,12,22}$ 
Table 3 Associations between sociodemographic and cultural factors for adherence to ART among 422 respondents with HIV/ AIDS

\begin{tabular}{|c|c|c|c|c|}
\hline \multirow[t]{2}{*}{ Variables } & \multicolumn{2}{|c|}{$\begin{array}{l}\text { Adhered to } \\
\text { ART (n) }\end{array}$} & \multirow[t]{2}{*}{$\begin{array}{l}\text { COR } \\
(95 \% \mathrm{CI})\end{array}$} & \multirow[t]{2}{*}{$\begin{array}{l}\text { AOR } \\
(95 \% \mathrm{Cl})\end{array}$} \\
\hline & Yes & No & & \\
\hline \multicolumn{5}{|c|}{ Disclosed HIV status } \\
\hline Yes & 357 & 14 & 1 & 1 \\
\hline No & 65 & 5 & $2(0.7 I, 5.88)$ & $0.93(0.28,3.0)$ \\
\hline \multicolumn{5}{|c|}{ Something bad happening after disclosure } \\
\hline Yes & 46 & 6 & $4.8(1.61,14.59)$ & $3.2(0.87,2.13)$ \\
\hline No & 267 & 8 & I & I \\
\hline \multicolumn{5}{|c|}{ Emotional/practical support } \\
\hline Yes & 141 & 14 & 1 & 1 \\
\hline No & 262 & 5 & $0.19(0.07,0.55)$ & $0.16(0.05,0.49)$ \\
\hline \multicolumn{5}{|c|}{ Being fully convinced of the need for ART } \\
\hline Yes & 401 & 18 & 1 & I \\
\hline No & 2 & 1 & $0.09(0.08,1.04)$ & $2.3(0.89,7.21)$ \\
\hline \multicolumn{5}{|c|}{ Use of TCAM } \\
\hline Yes & 274 & 17 & $4(0.91,17.58)$ & $4.7(1.06,21.22)$ \\
\hline No & 129 & 2 & 1 & 1 \\
\hline
\end{tabular}

Notes: All study participants were from the Debrebrihan Referral Hospital and Health Center, Northeast Ethiopia. Data were collected between December 20II and January 2012.

Abbreviations: ART, antiretroviral therapy; $n$, number of respondents; COR, corrected odds ratio; $\mathrm{Cl}$, confidence interval; $\mathrm{AOR}$, adjusted odds ratio; TCAM, traditional, complementary, and alternative medicine.

Possibly, the differences might arise from differences in methodology and study subjects.

Although the level of adherence was shown to be high in this study, a significant number of respondents reported that attending a religious place, fasting, and using holy water were reasons that made it inconvenient to take ARV medication according to the schedule. Taking the medication at irregular times alters the pharmacokinetic and pharmacodynamic effects of ARV medication. This type of inconsistency may exacerbate the occurrence of virologic failure and drug resistance. The causes of missing doses or nonadherence in this study are similar to those in other studies; these reasons include simply forgetting (63\%) and side effects $(16 \%){ }^{8-10,21}$

\section{Factors associated with adherence}

Consistent adherence is associated with better outcomes, including improved quality of life, higher CD4 count, and lower health care costs. ${ }^{20}$ Studies have shown that among key factors of medication adherence are the acceptance of the diagnosis, understanding the consequences of not taking the medicine, improvement in the medicine, and support from families and friends. ${ }^{22}$ The current study also showed that having emotional and practical support (AOR $0.16[95 \%$ CI $0.05-0.49]$ ) was positively and statistically associated with the adherence level among ART users. This finding is different from results of the study done in Ethiopia that showed parents who got free treatment $(0.39[0.16,0.92])$ and children who had received nutritional support $(0.34$ $[0.14,0.79])$ from the clinic did not adhere to ART more than those who paid for ART and did not get nutritional support. ${ }^{6}$ The possible differences might arise from differences in the methodology and the study subjects.

In this study, we found a statistical association between the use of TCAM (AOR 4.7 [95\% CI 1.06-21.22]) and adherence; PLWHA who received ART while using TCAM were 4.7 times more likely to miss at least one dose of treatment than those who did not use TCAM. A research synthesis done on complementary and alternative medicine used among HIV-positive people shows that a high proportion of HIV-positive individuals report TCAM use. ${ }^{26}$ The findings from the current study are consistent with those from other studies. Users of traditional healing practices in Latino culture were less likely to attend medical appointments and had lower rates of HAART adherence for the 3 days prior to filling out the self-report. More recently, HIV-positive women who reported using orally administered TCAM to treat their HIV were more likely to report missing at least one dose of their prescribed HIV medication during 30 days prior to filling out the self-report. ${ }^{15}$

A cross sectional study done in Florida showed that some of the participants (17\%) preferred TCAM to ART, but more than half reported the use of TCAM, a finding which is similar to this study. ${ }^{19}$

In studies done in Ethiopia, Zambia, and Florida on barriers and facilitators to taking ARV medication while visiting a holy water place, preferences for alternative treatments were barriers to HAART adherence. ${ }^{6,23,24}$ No association was seen in the current study.

Communication about TCAM use by patient-care providers would presumably reduce the risk for adverse health outcomes that may result from drug interactions or misuse of conventional medicine. Spiritual options may be interpreted as superior alternatives and contribute to hampering adherence to ART. ${ }^{25}$ However, no association was found in this study.

The strength of this study was addressing adherence and associated factors by using quantitative approaches; however, this study had its limitations as well. The cross-sectional nature of the study did not allow the temporal and cause-effect relationships between various factors and adherence to be addressed. Moreover, adherence is a dynamic process which cannot be predicted at a single point in time, but the study did measure 
snapshots of adherence and factors affecting adherence. Although this study tried to minimize social desirability bias, self-reported adherence may overstate true adherence more than other methods of measuring adherence. This possibility necessitates the inclusion of other methods of measuring adherence to support the consistency of the reported rate.

\section{Conclusion}

Adherence to ART at Debrebrihan Referral Hospital and Health Center was higher than in previous studies done on levels of adherence to ART. The covariate that is positively associated with adherence to ART is emotional and practical support. The use of TCAM is associated with a risk of nonadherence that is almost five times higher than for nonTCAM users. Strengthening emotional and other practical support and the promotion of the integration of TCAM with the proper use of ART for PLWHA are mandatory to enhance adherence and to minimize nonadherence by TCAM users; both of these strategies are recommended.

\section{Acknowledgments}

My deepest gratitude and appreciation goes to my advisors at Amhara Regional Health Bureau and the health workers from Debrebrihan Referral Hospital and Health Center for their contributions throughout the development of this research.

\section{Author contributions}

Throughout the study, from topic selection and preparation through finalization, many aspects of the project were done by Abush Kebede Ketema. The manuscript preparation, editing, and submission to the journal were done by Zewdu Shewangizaw Weret. All authors contributed toward data analysis, drafting and revising the paper and agree to be accountable for all aspects of the work.

\section{Disclosure}

We confirm that this research is our original paper and that there is no conflict of interest in this work.

\section{References}

1. Joint United Nations Programme on HIV and AIDS and World Health Organization. AIDS Epidemic Update. Geneva: Joint United Nations Programme on HIV and AIDS; 2007. Available from: http://data.unaids. org/pub/EPISlides/2007/2007_epiupdate_en.pdf. Accessed.

2. Federal HIV/AIDS Prevention and Control Office. Report on Progress towards Implementation of the UN Declaration of Commitment on HIV/AIDS. Addis Ababa: Federal HIV/AIDS Prevention and Control Office; 2010. Available from: http://data.unaids.org/pub/Report/2010/ ethiopia_2010_country_progress_report_en.pdf. Accessed.
3. World Health Organization. Adherence to Long Term Therapies: Evidence for Action. Geneva: World Health Organization; 2003. Available from: http://whqlibdoc.who.int/publications/2003/9241545992. pdf. Accessed.

4. Muluneh, Ezra. "Adherence to ART and its associated factors among HIV Aids Patients in Addis Ababa." Science and Technology against Microbial Pathogens: Research, Development and Evaluation, Proceedings of the International Conference on Antimicrobial Research (ICAR2010), Valladolid, Spain, 3-5 November 2010. Singapore, Singapore: World Scientific; 2011.

5. Zou J, Yamanaka Y, John M, Watt M, Ostermann J, Thielman N. Religion and HIV in Tanzania: influence of religious beliefs on HIV stigma, disclosure and treatment attitudes. BMC Public Health. 2009; 9:75.

6. Biadglign S, Deribew A, Amberbir A, Deribe K. Adherence to highly active antiretroviral treatment and its correlates among HIV infected paediatric patients in Ethiopia. BMC Pediatrics. 2008;8:53.

7. Kremer H, Ironson G, Schneiderman N, Hautzingeret M. To take or not to take: decision-making about antiretroviral treatment in people living with HIV/AIDS. AIDS Patient Care STDS. 2006;20(5):335-349.

8. Markos E, Worku A, Davey G. Adherence to antiretroviral treatment in PLWHA at Yirgalem Hospital, South Ethiopia. Ethiopian Journal of Health Development. 2009;22(2):174-179.

9. Tiyou A, Belachew T, Alemseged F, Biadgilign S. Predictors of adherence to ART among people living with HIV/AIDS in resource limited settings of southwest Ethiopia. AIDS Res Ther. 2010;7:39.

10. Curioso WH, Kepka D, Cabello R, Segura P, Kurth AE. Understanding the facilitators and barriers of antiretroviral adherence in Peru: a qualitative study. BMC Public Health. 2010;10:13.

11. World Health Organization. Traditional Medicine Growing Needs and Potential. Geneva: World Health Organization; 2002. Available from: http://whqlibdoc.who.int/hq/2002/WHO_EDM_2002.4.pdf?ua=1. Accessed.

12. Peltzer K, Friend-du Preez N, Ramlagan S, Fomundam H, Anderson J. Traditional complementary and alternative medicine and antiretroviral treatment adherence among HIV patients in Kwazulu-Natal, South Africa. Afr J Tradit Compliment Altern Med. 2009;7(2):125-137.

13. Berhanu Z. Assessment - HIV/AIDS Care and Support at Holy Water Sites in Addis Ababa [doctoral thesis]. Addis Ababa: Addis Ababa University; 2006.

14. Plus News Ethiopia: church endorses 'holy water' and antiretroviral, as people flock to miracle mountain. 2007 May 25 Available from: http:// www.plusnews.org/report.aspx?Reportld=72375.

15. Littlewood RA, Vanable PA. Complementary and alternative medicine use among HIV positive people. AIDS Care. 2008;20(8):1002-1018.

16. Chen WT, Shiu CS, Simoni J, et al. Attitudes toward antiretroviral treatment and complementary and alternative medicine in Chinese patients infected with HIV. J Assoc Nurses AIDS Care. 2009;20(3): 203-217.

17. Milan FB, Arnsten JH, Klein RS, et al. Use of complementary and alternative medicine in inner-city persons with or at risk for HIV. AIDS Patient Care STDs. 2008;22(10):811-816.

18. Ashly Owen-Smith, Frances McCarty, Dana Hankerson-Dyson, Ralph Di Clementa. Prevalence and predictors of complementary and alternative medicine use in Africa-Americans with acquired immune deficiency syndrome. Focus Altern Complement Ther. 2012;17(1);33-42.

19. Maskew M, Macphail P, Menezes C, Rubel D. Lost to follow up: contributing factors and challenges in South African patients on antiretroviral therapy. SAfr Med J. 2007;97(9):853-857.

20. Boyles TH, Wilkinson IS, Leisegang R, Maartens G. Factors influencing in care after starting antiretroviral therapy in a rural South African programme. PLoS One. 2011;6(5):e19201.

21. Wang $\mathrm{H}$, Zhou J, He G, et al. Consistent antiretroviral treatment is associated with improved quality of life, CD4 counts, and reduced hospital costs in central China. AIDS Res Hum Retroviruses. 2009;25(8):757-763. 
22. Ncaca LN, Kranzer K, Orrell C. Treatment interruption and variation in tablet taking behaviour results in viral failure: a case control study of Cape Town, South Africa. PloS One. 2011;6(8):e23088.

23. Biadgilign S, Deribew A, Amberbir A, Deribe K. Barrier and facilitators to antiretroviral medication adherence among HIV infected paediatric patients in Ethiopia: a qualitative study. SAHARA J. 2009;6(4):148-154.

24. Sanjabo N, Frich JC, Fretheim A. Barriers and facilitators to patients' adherence to antiretroviral treatment in Zambia: a qualitative study. SAHARA J. 2008;5(3):136-143.
25. Roura M, Roy Nsigaye R, Benjamin Nhandi B, et al. "Driving the devil away": qualitative insights into miraculous cures for AIDS in a rural Tanzanian ward. BMC Public Health. 2010;10:427.

26. Lorenc A, Robinson N. A review of the use of complementary and alternative medicine and HIV: issues for patient care. AIDS Patient Care STDs. 2013; 27(9):503-510.

\section{Publish your work in this journal}

HIV/AIDS - Research and Palliative Care is an international, peerreviewed open-access journal focusing on advances in research in HIV, its clinical progression and management options including antivira treatment, palliative care and public healthcare policies to contro viral spread. The journal welcomes original research, basic science, clinical \& epidemiological studies, reviews \& evaluations, expert opinion \& commentary, case reports \& extended reports. The manuscript management system is completely online and includes a very quick and fair peer-review system. Visit http://www.dovepress.com/ testimonials.php to read real quotes from published authors.

Submit your manuscript here: http://www.dovepress.com/hivaids---research-and-palliative-care-journal 